\title{
Effect of method of delivery of sodium butyrate on rumen development in newborn calves
}

\author{
P. Górka, ${ }^{\star 1}$ Z. M. Kowalski, ${ }^{\star}$ P. Pietrzak,† A. Kotunia,‡ W. Jagusiak,§ J. J. Holst,\# P. Guilloteau,II \\ and R. Zabielski† \\ *Department of Animal Nutrition and Feed Management, University of Agriculture in Krakow, 31-120 Krakow, Poland \\ †Department of Physiological Sciences, Faculty of Veterinary Medicine, Warsaw University of Life Sciences, 02-766 Warsaw, Poland \\ $\ddagger$ The Kielanowski Institute of Animal Physiology and Nutrition, Polish Academy of Sciences, 05-110 Jablonna, Poland \\ §Department of Genetics and Animal Breeding, University of Agriculture in Krakow, 31-120 Krakow, Poland \\ \#Department of Biomedical Sciences, University of Copenhagen, The Panum Institute, 2200-Copenhagen, Denmark \\ IIINRA, UMR 1079, Système d'Elevage, Nutrition Animale et Humaine (SENAH), Domaine de la Prise, 35590 Saint-Gilles, France
}

\begin{abstract}
The effect of sodium butyrate (SB) supplementation in milk replacer $(\mathrm{MR})$ or in starter mixture $(\mathrm{SM})$ or in both MR and SM on performance, selected blood parameters, and rumen development in newborn calves was determined. Twenty-eight male calves with a mean age of $5( \pm 1)$ d were randomly allocated into 1 of 4 groups (7 animals per group) and fed (1) MR and $\mathrm{SM}$, both without $\mathrm{SB}$ ( $\mathrm{MR}^{-}$and $\mathrm{SM}^{-}$, respectively); (2) $\mathrm{MR}^{-}$and SM supplemented with SB encapsulated within a triglyceride matrix $\left(\mathrm{SM}^{+}, 0.6 \%\right.$ as fed; $30: 70$ butyrate-to-triglyceride matrix); (3) MR supplemented with crystalline $\mathrm{SB}\left(\mathrm{MR}^{+}, 0.3 \%\right.$ as fed) and $\mathrm{SM}^{-}$; or (4) $\mathrm{MR}^{+}$and $\mathrm{SM}^{+}$. The MR was offered in an amount equal to $10 \%$ of the initial body weight (BW) of each calf. The SM was blended with whole corn grain (50/50; $\mathrm{wt} / \mathrm{wt})$ and offered ad libitum as a starter diet $(0.3 \%$ encapsulated within triglyceride matrix $\mathrm{SB}$ when $\mathrm{SM}^{+}$ was fed) from the first day of the trial. Calves were slaughtered at d 21 of a trial (mean age $26 \pm 1 \mathrm{~d}$ ). Addition of SB into $\mathrm{MR}\left(\mathrm{MR}^{+}\right)$positively affected $\mathrm{BW}$ and average daily gain, tended to decrease the number of days with electrolyte therapies from d 0 to 7 , and tended to positively affect fecal consistency from $\mathrm{d} 8$ to 14 of the trial. Inclusion of SB into SM $\left(\mathrm{SM}^{+}\right)$increased starter diet intake from d 15 to 21 , decreased the number of days with scours, and tended to decrease the number of days with electrolyte therapies in the whole trial period. Both $\mathrm{MR}^{+}$and $\mathrm{SM}^{+}$increased plasma glucose in the whole trial period and $\mathrm{MR}^{+}$increased total serum protein at $\mathrm{d} 14$. The $\mathrm{SM}^{+}$increased plasma glucagon-like peptide-2 (GLP-2) concentration at d 7 of the trial when compared with the concentration at $\mathrm{d}$ 0. Both $\mathrm{MR}^{+}$and $\mathrm{SM}^{+}$increased reticulorumen
\end{abstract}

Received January 11, 2011.

Accepted June 20, 2011.

${ }^{1}$ Corresponding author: p.gorka@ur.krakow.pl weight and papillae length and width. Based on these results, it can be concluded that addition of SB in MR positively affected BW gain, health, and some metabolic intermediates of calves and it stimulated rumen development indirectly, whereas SB supplementation in SM stimulated rumen development directly. Addition of SB both in MR and SM could be recommended for rearing calves.

Key words: milk replacer, gastrointestinal tract, rumen papillae, glucagon-like peptide- 2

\section{INTRODUCTION}

Due to economic reasons, early weaning of calves from whole milk (WM) or milk replacer (MR) even as early as 3 to 4 wk of age is being practiced on many dairy farms. However, early weaning requires rapid development of the gastrointestinal tract (GIT), especially the rumen (Baldwin et al., 2004), as it determines solid feed intake and, thus, growth and health of calves after weaning (Greenwood et al., 1997a).

If calves are early weaned, the composition and physical structure of solid feed is critical, as it is the main dietary stimulator of rumen development (Tamate et al., 1962; Lesmeister and Heinrichs, 2004). It is well documented that butyric acid and, to a lesser extent, propionic acid, are the primary chemical stimulators of rumen epithelium development (Tamate et al., 1962; Mentschel et al., 2001). Therefore, feeding calves solid feeds rich in starch and simple sugars promoting production of these VFA in the rumen is widely accepted (Lesmeister and Heinrichs, 2004; Hill et al., 2008) as a means of enhancing development. If butyric acid is the main stimulator of rumen epithelium development, a direct addition of butyric acid or its sodium salt to the starter mixture (SM) could accelerate rumen development (Hill et al., 2007b). However, to our knowledge, the effect of such a feeding practice on calf rumen development has not been determined so far. 
Recently, sodium butyrate (SB) was shown to be an important regulator and stimulator of epithelial cell proliferation, differentiation, and apoptosis in the stomach and small intestine of calves and piglets (Kotunia et al., 2004; Mazzoni et al., 2008; Guilloteau et al., 2009) and of pancreatic juice secretion (Guilloteau et al., 2004 and 2010). Addition of SB in MR stimulated pancreatic secretion and intestinal cell proliferation, villus growth, and brush border and pancreatic enzyme activity, which resulted in improved digestibility and better performance and health of calves (Hill et al., 2007a; Guilloteau et al., 2009, 2010). Although liquid feed in the preruminant calf bypasses the reticulorumen via the reticular groove it might also affect rumen development indirectly. Liquid feed determines the growth and health of animals and thus, solid feed intake and consequently, rumen development (Niwińska and Strzetelski, 2005; Khan et al., 2007). It is also known that liquid feed type and composition affect the development and function of distal GIT, particular abomasum and small intestine. Widely accepted use of MR in dairy calf nutrition instead of WM slows small intestine development (Seegraber and Morrill, 1986; Blättler et al., 2001). This negative effect of feeding calves MR on small intestine development impairs the performance of calves, decreases solid feed intake, and as a result, slows rumen development (Górka et al., 2011). Use of supplemental SB in MR partially mitigated the negative effect of MR (Górka et al., 2011).

Based on the above considerations, we hypothesized that addition of SB both in MR and SM could enhance rumen development either directly (SB in SM) or indirectly (SB in MR) and simultaneous addition of SB in both MR and SM would be the most effective means of delivery. Thus, the aim of this study was to determine the effect of SB inclusion in MR or SM or in both MR and SM on rumen development in neonatal calves, as well as on their growth, health status, and some blood parameters.

\section{MATERIALS AND METHODS}

\section{Animals and Diets}

The study described here was a part of a scientific project published elsewhere (Górka et al., 2011). The animal study protocol was approved by the Local Ethics Committee (Krakow, Poland) before the onset of the trial. The trial was conducted at a dairy farm (Top Farms Głubczyce Sp. z o.o.) located in Southern Poland (Głubczyce). Twenty-eight clinically healthy male calves (Holstein or Holstein $\times$ Limousin) with mean age of 5 $( \pm 1)$ d were randomly allocated to a $2 \times 2$ factorial experiment ( 7 calves per group) and fed (1) MR and SM, both without $\mathrm{SB}\left(\mathbf{M R}^{-}\right.$and $\mathbf{S M}^{-}$, respectively; group $\mathbf{M R}^{-} / \mathbf{S M}^{-}$); (2) $\mathrm{MR}^{-}$and SM supplemented with SB encapsulated within a triglyceride matrix $\left[\mathbf{S M}^{+}, 0.6 \%\right.$ as fed (30:70 butyrate-to-triglyceride matrix); group $\mathbf{M R}^{-} / \mathbf{S M}^{+}$; (3) MR supplemented with crystalline $\mathrm{SB}\left(\mathbf{M} \mathbf{R}^{+}, 0.3 \%\right.$ as fed) and $\mathrm{SM}^{-}$(group $\left.\mathbf{M} \mathbf{R}^{+} / \mathbf{S M}^{-}\right)$; or (4) $\mathrm{MR}^{+}$and $\mathrm{SM}^{+}$(group $\mathbf{M R}^{+} / \mathbf{S M}^{+}$).

Before the onset of the trial, up to d 2 of life, calves were fed $2.5 \mathrm{~L}$ of colostrum and transition milk, and thereafter 2.5 L of WM given twice per day, without access to solid feeds. Colostrum was fed within the first $2 \mathrm{~h}$ of life. The calves were kept in a ventilated barn in individual pens $(1.5 \times 1.2 \mathrm{~m})$ with rubber flooring covered with sawdust to avoid straw intake. Each calf was in the trial over a period of $21 \mathrm{~d}$, until the age of $26( \pm 1)$ d, when killed.

Calves were fed individually. The $\mathrm{MR}^{-}$or $\mathrm{MR}^{+}$(Primolac; Polmass S.A., Bydgoszcz, Poland) were mixed (1:9) with warm water (about $40^{\circ} \mathrm{C}$ ) and fed from a bucket with a teat, at 0800 and 1500 h daily. Crystalline SB (VetAgro, Reggio Emilia, Italy) was introduced into the $\mathrm{MR}^{+}$by the MR manufacturer. Milk replacer was offered at $10 \%$ of calf $\mathrm{BW}$ at the initiation of the experiment. The MR was introduced to the calf diet gradually over the first $3 \mathrm{~d}$ of the trial, beginning at $50 \%$ of the final target volume. Refusals of MR were recorded daily.

The $\mathrm{SM}^{-}$or $\mathrm{SM}^{+}$(KCJ; Polmass S.A.; $37-38 \%$ of $\mathrm{CP})$ was blended with whole corn grain $(50 / 50$; wt/ wt) and offered as a starter diet (StDt, about 24 and $15 \%$ of CP and NDF in DM, respectively) once daily ad libitum, after the morning MR feeding $(0900 \mathrm{~h})$, beginning on the first day of the study. The $\mathrm{SM}^{+}$contained SB encapsulated within a triglyceride matrix $(30 \%$; VetAgro) in an amount equal to $0.6 \%$ as fed, such that the StDt contained $0.3 \%$ encapsulated SB $(0.09 \%$ SB by weight). The aim of encapsulation of $\mathrm{SB}$ was to slow the butyric acid release in the rumen. Refusals of StDt were collected daily and samples from each calf were divided by sieving into SM and whole corn grain, for calculation of $\mathrm{CP}$ and $\mathrm{ME}$ intake.

Samples of $\mathrm{MR}^{-}$and $\mathrm{MR}^{+}$powder, $\mathrm{SM}^{-}$and $\mathrm{SM}^{+}$, and corn grain were collected weekly and pooled for analysis of DM, ash, CP, crude fat, crude fiber, NDF, and ADF using standard procedures (AOAC, 2000), and for starch (Faisant et al., 1995). The ME content was calculated based on NRC (2001) equations.

\section{Measurements and Observations}

The calves were weighed on d 0 (initial weight), 7 , 14, and 21 (end weight) of the trial. Fecal score, including fluidity (4-point scale: $1=$ normal, $4=$ diarrhea), consistency $(5$-point scale: $1=$ normal, $2=$ frothy, $3=$ 
mucous, $4=$ sticky, $5=$ hard constipation), and smell (3-point scale: $1=$ normal, $3=$ disgusting) were determined daily according to Larson et al. (1977). Body condition (5-point scale: $1=$ very bad, $5=$ very good) was scored based on general appearance. Every abnormal health condition, such as fever and pneumonia, as well as every veterinary treatment, such as antibiotic and electrolyte therapy, was documented. Calves with diarrhea were treated with a commercial electrolyte solution (Rehydrat, Biowet Puławy Sp. z o.o., Puławy, Poland). Electrolyte therapy was initiated when fecal fluidity score equaled to 3 or 4 and antibiotic therapy was initiated when rectal temperature was over $39.5^{\circ} \mathrm{C}$.

\section{Blood Parameters}

Blood samples were taken from the external jugular vein at the beginning of the trial, and then weekly, before morning liquid feeding. Tubes containing EDTA (VT-100 STK, $0.1 \mathrm{~mL}$ of EDTA, $0.47 \mathrm{~mL} / \mathrm{L}: 21 \mathrm{wt} / \mathrm{vol}$ \%; CML, Nemours, France) and aprotinin (10,000 IU/ mL; Trasylol; Bayer Pharma SAS, Puteaux, France; only for GLP-2 analysis) for plasma separation were used, whereas serum was obtained after leaving blood samples at room temperature $\left(21^{\circ} \mathrm{C}\right)$ until a clot formed. Blood was centrifuged at $2,300 \times g$ for $10 \mathrm{~min}$ at $8^{\circ} \mathrm{C}$. Plasma and serum were frozen and stored at $-20^{\circ} \mathrm{C}$ until further analysis. Plasma glucose, urea, BHBA, and serum total protein concentrations were determined using an automatic chemical analyzer (Hitachi 902; Hitachi, Tokyo, Japan). For serum total protein, plasma glucose, and urea concentration determinations, the BioSystems (Barcelona, Spain) kits were used, whereas for plasma BHBA determination, the kits were provided by Diagnostic Systems Laboratories Inc. (Sinsheim, Germany).

Glucagon-like peptide-2 (GLP-2) concentration in plasma was determined by radioimmunoassay after extraction of plasma with $70 \%$ ethanol, employing antiserum code no. 92160 and standards of human GLP-2 (proglucagon 126-158, a gift from Novo Nordisk A/S, Bagsværd, Denmark) and monoiodinated Tyr-12 GLP-1 (specific activity $>70 \mathrm{MBq} / \mathrm{nmol}$; Hartmann et al., 2000). The antiserum was directed against the $\mathrm{N}$ terminus of GLP-2 and, therefore, measured only fully processed GLP-2 of intestinal origin. The sensitivity for the assay was below $2 \mathrm{pmol} / \mathrm{L}$, and an intra-assay coefficient of variation below $6 \%$.

\section{Rumen Development}

At the end of the trial, all calves (26 $\pm 1 \mathrm{~d}$ of age) were killed by captive bolt stunning, and exsanguinated. On the day of slaughter, the MR was not offered.
The forestomachs and abomasum were dissected. $\mathrm{Ru}-$ men fluid was sampled for VFA (Erwin et al., 1961), $\mathrm{N}^{-} \mathrm{NH}_{3}$ (Conway, 1962), and $\mathrm{pH}$ determination. The reticulorumen, omasum, and abomasum were separated, emptied, rinsed repeatedly with water, drained, and weighed individually.

One square centimeter of the whole thickness samples from the left side of the cranial dorsal sac and left side of the cranial ventral sac of the rumen were fixed in $4 \%$ buffered formaldehyde for $5 \mathrm{~d}$ before being stored in ethanol until embedding in paraffin. Serial histological sections were stained with hematoxylin and eosine for morphometric analysis under a light microscope, including papillae length and width, and rumen muscle layer thickness. Five to eight slides for each tissue sample were prepared. For each tissue sample, 30 measurements were performed using an optical binocular microscope (Olympus BX 61; Olympus Europa GmbH, Hamburg Germany) coupled via a digital camera to a $\mathrm{PC}$ computer equipped with a cell^P (Olympus Europa $\mathrm{GmbH}$ ) software.

\section{Statistical Analysis}

Body weight, ADG, total DM, CP and ME intake, StDt and whole corn grain intake, parameters of health status, and concentration of selected blood parameters in the particular weeks of the experiment were analyzed as repeated measures using the PROC MIXED statement of the SAS (SAS Institute, 2002). Data on DM, $\mathrm{CP}$ and ME intake, fecal score, number of days with scours, number of days with antibiotics, and number of days with electrolyte therapies were pooled by week for analysis. The statistical model included calf as a random effect, and experimental group and its interaction with time as a fixed effect (Littell et al., 1998). The number of Holstein $\times$ Limousin animals ranged between 2 to 5 in each group and the effect of breed was incorporated into the statistical models as a fixed effect.

The statistical model used for repeated measure analyses was

$$
Y_{c g t}=\mu+\alpha_{g}+\beta_{t}+(\alpha \beta)_{g t}+\gamma(\alpha)_{c g}+\delta_{c}+e_{c g t},
$$

where $Y_{c g t}=$ an observation value for BW, ADG, total $\mathrm{DM}, \mathrm{CP}$ and ME intake, StDt and whole corn grain intake, parameters of health status, and concentration of selected parameters in blood taken from calf $c$ from group $g$ at time $t ; \mu=$ overall mean for the population; $\alpha_{g}=$ fixed effect of group $g$, where $g=$ group $\mathrm{MR}^{-} /$ $\mathrm{SM}^{-}, \mathrm{MR}^{-} / \mathrm{SM}^{+}, \mathrm{MR}^{+} / \mathrm{SM}^{-}$, or $\mathrm{MR}^{+} / \mathrm{SM}^{+} ; \beta_{t}=$ fixed effect of time $t$, where $t=\mathrm{d} 0,7,14$, or 21 for $\mathrm{BW}$ and blood parameters or $t=$ week of the trial (d 0 
to 7 , d 8 to 14 , or d 15 to 21) for ADG, DM, CP and ME intake, parameters of health status, and StDt and whole corn grain intake; $(\alpha \beta)_{g t}=$ fixed interaction of effect of group $g$ and time $t ; \gamma(\alpha)_{c q}=$ random effect of calf $c$ nested within group $g ; \delta_{c}=$ fixed effect of calf breed, where breed $=$ Holstein or Holstein $\times$ Limousin; and $e_{c g t}=$ error associated with the measurement taken from calf $c$ from group $g$ at time $t$.

Means for the whole trial period for BW gain, ADG, total DM, CP, ME intake, StDt and whole corn grain intake, fecal score, number of days with scours, number of days with antibiotics, and number of days with electrolyte therapies, as well as stomach development parameters, were subjected to ANOVA using PROC GLM (SAS Institute, 2002). The statistical model used was

$$
Y_{c g}=\mu+\alpha_{g}+\delta_{c}+e_{c g}
$$

where $Y_{c g}=$ an observation value for average $\mathrm{BW}$ gain, $\mathrm{ADG}, \mathrm{DM}, \mathrm{CP}$ and $\mathrm{ME}$ intake, StDt and whole corn grain intake, concentration of selected blood parameters, parameters of health status, and stomach and small intestine development parameters taken from calf $c$ from group $g ; \mu=$ overall mean for the population; $\alpha_{g}=$ fixed effect of group $g$, where $g=$ group of calves (as above); $\delta_{c}=$ fixed effect of calf breed; and $e_{c g}=$ error associated with the measurement taken from calf $c$ from group $g$.

Furthermore, the effect of initial age of the calves $( \pm 1 \mathrm{~d})$ was tested. Because it was not significant $(P>$ $0.05)$, it was removed from statistical models. The initial BW of calves and initial plasma glucose, urea, BHBA, GLP-2, and initial serum total protein concentrations were used as covariates in the statistical analysis for ADG and plasma glucose, urea, BHBA, GLP-2, and total serum protein concentrations, respectively. For parameters of rumen development, mean StDt intake in the whole trial was taken as a covariate.

The scientific hypothesis was verified based on preplanned contrasts $\left(\mathrm{MR}^{+}\right.$vs. $\mathrm{MR}^{-}, \mathrm{SM}^{+}$vs. $\mathrm{SM}^{-}$, and $\mathrm{MR} \times \mathrm{SM})$. The ESTIMATE statement of the SAS was used for treatment comparisons at a particular point of time in repeated measure analysis, and the CONTRAST statement of the SAS was used for comparison of means obtained in the whole trial and for stomach and small intestine development parameters. Significance was declared at $P<0.05$ and tendencies at $P<0.10$.

\section{RESULTS}

\section{Performance and Health}

The chemical composition of the experimental feeds is presented in Table 1. The DM, CP and ME intake,
BW, ADG, and DMI of the StDt changed $(P<0.01)$ during the trial period (Table 2). Calves fed $\mathrm{MR}^{+}$had higher $(P<0.05) \mathrm{BW}$ on $\mathrm{d} 7,14$, and 21 of the trial as compared with calves fed $\mathrm{MR}^{-}$. Also calves fed $\mathrm{MR}^{+}$ had higher $(P=0.04)$ ADG from d 0 to 7 and tended to have higher $(P=0.09) \mathrm{ADG}$ and $\mathrm{BW}$ gain for the whole trial period as compared with calves fed $\mathrm{MR}^{-}$. On the other hand, calves fed $\mathrm{SM}^{+}$had higher $(P=$ 0.05) DMI of StDt from d 15 to 21 of the trial. As a consequence, DM and ME intake was higher $(P<0.05)$ and $\mathrm{CP}$ intake tended to be higher $(P=0.07)$ from $\mathrm{d}$ 15 to 21, and DM and ME intake in the whole trial period tended to be higher $(P<0.10)$ for calves fed $\mathrm{SM}^{+}$. No interaction between main effects for performance parameters was observed. Because most calves lost BW during the current study (mainly fed $\mathrm{MR}^{-}$), feed conversion was not calculated.

Calves selected more SM from the StDt and avoided whole corn grain, especially in the first week of the trial (data not shown). Whole corn grain intake increased with calf age and mean intake for the whole trial period amounted $36 \%$ of StDt intake (on feed basis). No intake differences existed between treatments, with the exception of $\mathrm{d} 8$ to 14 of the trial when animals fed $\mathrm{MR}^{+}$ tended to $(P=0.08)$ consume less whole corn grain then calves fed $\mathrm{MR}^{-}$.

Calves were generally healthy during the trial and required only few veterinary interventions (Table 3). One calf died at d 2 of the study (navel inflammation and septicemia) and was replaced. The MR supplemented with SB tended to decrease $(P=0.07)$ the number of days with electrolyte therapies from d 0 to 7 of the trial. From d 8 to 14, an interaction between main effects for fecal fluidity, number of days with scours, and days with electrolyte therapies was observed. During the 8- to 14-d period, calves from the $\mathrm{MR}^{+} / \mathrm{SM}^{-}$group had the most, calves from $\mathrm{MR}^{-} / \mathrm{SM}^{-}$and $\mathrm{MR}^{-} / \mathrm{SM}^{+}$ groups were intermediate, and calves from $\mathrm{MR}^{+} / \mathrm{SM}^{+}$ group had the fewest days with scours and electrolyte therapies. It is noteworthy that calves from the $\mathrm{MR}^{+} /$ $\mathrm{SM}^{+}$group had the fewest scours and required no electrolyte therapies from d 8 to 14 of the trial. In addition, $\mathrm{SM}^{+}$tended to positively affect $(P=0.08)$ fecal consistency from d 15 to 21 and decreased $(P=0.03)$ the number of days with scours and tended to decrease $(P$ $=0.09$ ) the number of days with electrolyte therapies for the entire trial period. Moreover, calves fed $\mathrm{SM}^{+}$ required no antibiotic treatment from d 8 to 15 . No effect of $\mathrm{MR}^{+}$and $\mathrm{SM}^{+}$on body condition of calves was observed (data not shown).

\section{Blood Parameters}

Serum total protein, plasma glucose, BHBA, and GLP-2 concentrations changed $(P<0.01)$ during the 
GÓRKA ET AL.

Table 1. Chemical composition of experimental feeds (on DM basis)

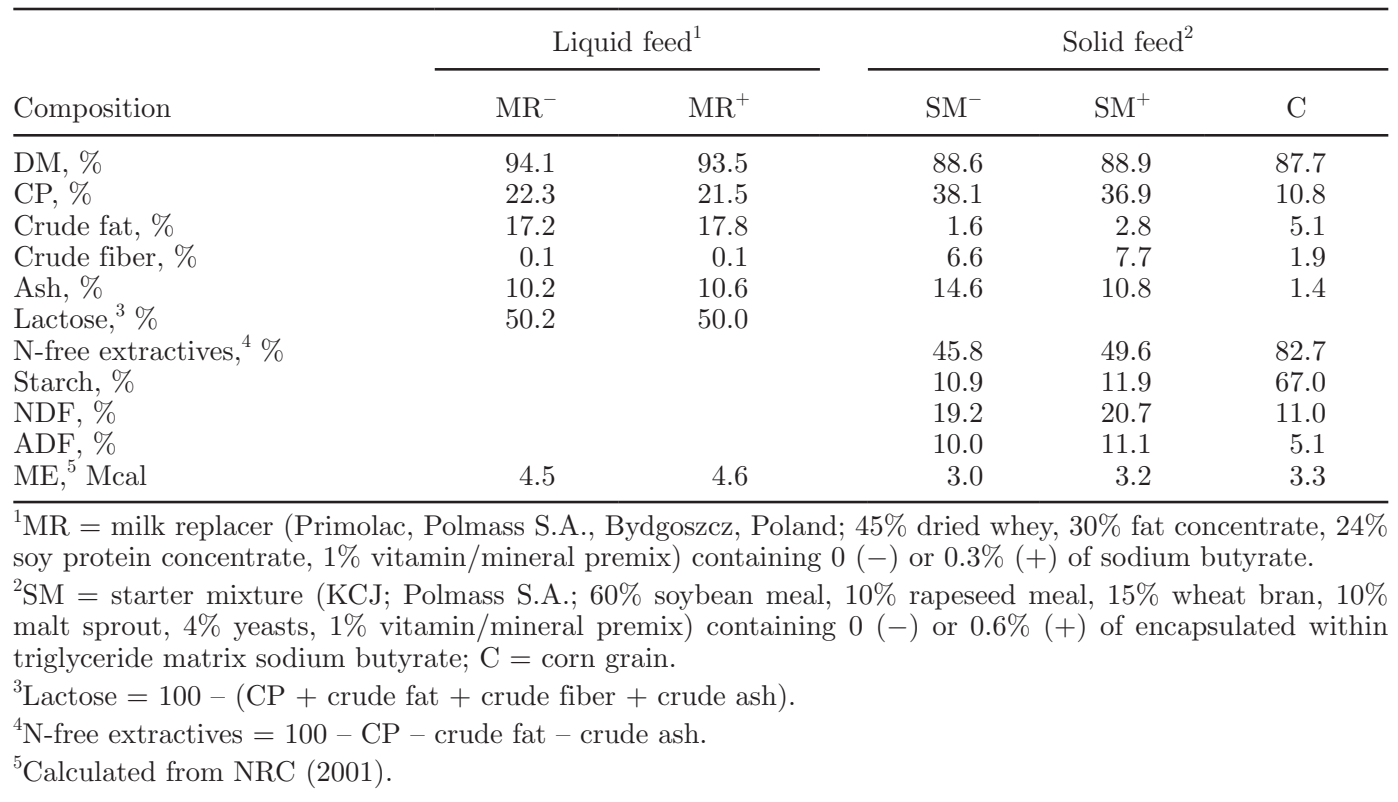

whole trial period (Table 4). Serum total protein and plasma glucose concentrations decreased with age, whereas plasma BHBA and GLP-2, both absolute concentration (data not shown) and concentration expressed as a relative value to $\mathrm{d} 0$, increased at $\mathrm{d} 7$ and then decreased. A substantial decrease in serum total protein and plasma glucose concentrations from d 0 to 7 was observed and it continued until d 21 .

An interaction between main effects for serum total protein at $\mathrm{d} 7$ was found where the concentration was greatest for the $\mathrm{MR}^{-} / \mathrm{SM}^{+}$and $\mathrm{MR}^{+} / \mathrm{SM}^{-}$groups and lowest for the $\mathrm{MR}^{-} / \mathrm{SM}^{-}$and $\mathrm{MR}^{+} / \mathrm{SM}^{+}$groups. This interaction appears to be driven by a substantial decrease of serum total protein for calves from the $\mathrm{MR}^{-} /$ $\mathrm{SM}^{-}$group within the first $7 \mathrm{~d}$ of the trial. Calves fed $\mathrm{MR}^{+}$had higher serum total protein at d $14(P=0.05)$, and plasma glucose at d $21(P=0.04)$, and lower plasma BHBA at $\mathrm{d} 7(P<0.01)$. An interaction $(P<0.01)$ between main effects for plasma glucose in the whole trial period was observed where glucose was highest for calves from the $\mathrm{MR}^{-} / \mathrm{SM}^{+}$group, intermediate for those from the $\mathrm{MR}^{+} / \mathrm{SM}^{-}$and $\mathrm{MR}^{+} / \mathrm{SM}^{+}$groups, and lowest for calves from the $\mathrm{MR}^{-} / \mathrm{SM}^{-}$group. No effect of time or SB supplementation on plasma urea was found (data not presented).

No effect of treatment on absolute plasma GLP-2 concentration was observed (data not presented). At d 0 , the GLP-2 concentration varied widely from 5 to 68 $\mathrm{pmol} / \mathrm{L}$ and differed substantially among animals. At d 0 , the mean GLP-2 concentration was 23.9, 19.5, 25.8, and 16.9 for calves fed $\mathrm{MR}^{-}, \mathrm{MR}^{+}, \mathrm{SM}^{-}$, and $\mathrm{SM}^{+}$, respectively, and the absolute GLP-2 concentration at d 0 , which was taken as a covariate, had a significant $(P<0.01)$ effect in the statistical model. When plasma GLP-2 concentration was expressed in relative values as compared with the mean value at $\mathrm{d} 0$, calves fed $\mathrm{SM}^{+}$had a higher $(P=0.05)$ plasma GLP-2 increase at $\mathrm{d} 7$ relatively to $\mathrm{d} 0$ as compared with those fed $\mathrm{SM}^{-}$(Table 4).

\section{Rumen Development}

No treatment effects were observed on VFA and $\mathrm{NH}_{3}$ concentration in the rumen fluid or on rumen fluid $\mathrm{pH}$ (data not shown). Few interactions between main effects for anatomical and morphological parameters of rumen development were observed (Table 5). Reticulorumen weight was the greatest for calves from the $\mathrm{MR}^{-} / \mathrm{SM}^{+}$ group, intermediate for those from the $\mathrm{MR}^{+} / \mathrm{SM}^{-}$and $\mathrm{MR}^{+} / \mathrm{SM}^{+}$groups, and the lowest from those from the $\mathrm{MR}^{-} / \mathrm{SM}^{-}$group (interaction $\mathrm{MR} \times \mathrm{SM} ; P=0.05$ ). A similar tendency for whole stomach weight was found (interaction $\mathrm{MR} \times \mathrm{SM} ; P=0.09$ ). The $\mathrm{MR}^{+}$increased $(P=0.04)$ and $\mathrm{SM}^{+}$tended to increase $(P=0.06)$ reticulorumen weight, expressed as a percentage of whole stomach weight.

In the cranial dorsal sac of the rumen, calves fed $\mathrm{MR}^{+}$ tended to have greater papillae length $(P=0.08)$ and had greater papillae width $(P=0.02)$ and calves fed $\mathrm{SM}^{+}$had higher papillae length and papillae width $(P$ $<0.05)$. On the other hand, in the cranial ventral sac of the rumen, an interaction $(P=0.04)$ between main effects for papillae length was observed. Calves from the $\mathrm{MR}^{+} / \mathrm{SM}^{-}$group had the longest papillae in this loca- 
Table 2. The effect of sodium butyrate supplementation on the performance of calves and DM, CP, and ME intake

\begin{tabular}{|c|c|c|c|c|c|c|c|c|}
\hline \multirow[b]{2}{*}{ Variable } & \multicolumn{4}{|c|}{ Treatment $^{1}$} & \multirow[b]{2}{*}{$\mathrm{SE}$} & \multicolumn{3}{|c|}{ Contrast $^{2}$} \\
\hline & $\mathrm{MR}^{-} / \mathrm{SM}^{-}$ & $\mathrm{MR}^{-} / \mathrm{SM}^{+}$ & $\mathrm{MR}^{+} / \mathrm{SM}^{-}$ & $\mathrm{MR}^{+} / \mathrm{SM}^{+}$ & & $\mathrm{MR}$ & SM & I \\
\hline \multicolumn{9}{|l|}{$\mathrm{BW},{ }^{3} \mathrm{~kg}$} \\
\hline d 0 & 45.3 & 46.0 & 48.0 & 47.7 & 1.0 & NS & NS & NS \\
\hline d 7 & 44.2 & 45.7 & 48.6 & 47.8 & 1.1 & 0.05 & NS & NS \\
\hline d 14 & 43.9 & 45.2 & 48.2 & 47.9 & 1.0 & 0.02 & NS & NS \\
\hline d 21 & 45.6 & 46.8 & 49.9 & 49.7 & 1.1 & 0.01 & NS & NS \\
\hline $\mathrm{BW}$ gain, $\mathrm{kg}$ & 0.3 & 0.8 & 1.9 & 2.0 & 0.2 & 0.09 & NS & NS \\
\hline \multicolumn{9}{|l|}{$\mathrm{ADG},{ }^{3} \mathrm{~g} / \mathrm{d}$} \\
\hline d 0 to 7 & -153 & -48 & 91 & 10 & 37 & 0.04 & NS & NS \\
\hline d 8 to 14 & -51 & -72 & -61 & 10 & 33 & NS & NS & $\mathrm{NS}$ \\
\hline d 15 to 21 & 245 & 226 & 235 & 265 & 35 & NS & NS & NS \\
\hline In the whole trial & 14 & 36 & 88 & 95 & 40 & 0.09 & NS & NS \\
\hline \multicolumn{9}{|c|}{ DMI of starter diet ${ }^{3} \mathrm{~g} / \mathrm{kg}$ of BW } \\
\hline d 0 to 7 & 0.4 & 0.6 & 0.3 & 0.6 & 0.09 & NS & NS & NS \\
\hline d 8 to 14 & 2.0 & 2.6 & 1.9 & 2.0 & 0.21 & NS & NS & NS \\
\hline d 15 to 21 & 3.8 & 5.4 & 4.0 & 5.0 & 0.49 & NS & 0.05 & NS \\
\hline In the whole trial & 2.0 & 2.7 & 1.9 & 2.4 & 0.22 & NS & NS & NS \\
\hline \multicolumn{9}{|c|}{ Total DMI ${ }^{3} \mathrm{~g} / \mathrm{kg}$ of BW } \\
\hline d 0 to 7 & 7.1 & 7.2 & 7.3 & 7.3 & 0.1 & NS & NS & NS \\
\hline d 8 to 14 & 11.4 & 12.0 & 10.9 & 11.2 & 0.2 & NS & NS & NS \\
\hline d 15 to 21 & 13.5 & 15.0 & 12.1 & 14.3 & 0.5 & NS & $<0.01$ & NS \\
\hline \multirow{2}{*}{\multicolumn{9}{|c|}{$\begin{array}{l}\text { In the whole trial } \\
\text { Intake of } \mathrm{CP}^{3} \mathrm{~g} / \mathrm{kg} \text { of } \mathrm{BW}\end{array}$}} \\
\hline & & & & & & & & \\
\hline d 0 to 7 & 1.6 & 1.7 & 1.6 & 1.6 & 0.03 & NS & NS & NS \\
\hline d 8 to 14 & 2.6 & 2.8 & 2.5 & 2.5 & 0.06 & NS & NS & NS \\
\hline d 15 to 21 & 3.2 & 3.6 & 3.1 & 3.3 & 0.12 & NS & 0.07 & NS \\
\hline In the whole trial & 2.4 & 2.6 & 2.3 & 2.4 & 0.05 & NS & NS & NS \\
\hline \multicolumn{9}{|c|}{ Intake of ME ${ }^{3}$ Mcal $\times 10^{-3} / \mathrm{kg}$ of BW } \\
\hline d 0 to 7 & 30.1 & 31.0 & 32.1 & 32.4 & 0.6 & NS & NS & NS \\
\hline d 8 to 14 & 47.3 & 49.4 & 47.8 & 48.5 & 0.7 & NS & NS & $\mathrm{NS}$ \\
\hline d 15 to 21 & 54.0 & 59.1 & 54.7 & 58.6 & 1.5 & NS & 0.04 & NS \\
\hline In the whole trial & 42.3 & 45.2 & 43.1 & 44.8 & 0.6 & NS & 0.10 & NS \\
\hline \multicolumn{9}{|c|}{$\begin{array}{l}{ }^{1} \mathrm{MR}=\text { milk replacer containing } 0(-) \text { or } 0.3 \%(+) \text { of sodium butyrate; } \mathrm{SM}=\text { calf starter mixture containi } \\
\text { butyrate. } \\
{ }^{2} \mathrm{MR}=\text { main effects of } \mathrm{MR}^{+} \text {vs. } \mathrm{MR}^{-} ; \mathrm{SM}=\text { main effects of } \mathrm{SM}^{+} \text {vs. } \mathrm{SM}^{-} ; \mathrm{I}=\text { interaction of main effects. } \\
{ }^{3} \text { Significant effect of time }(P<0.01) \text {. }\end{array}$} \\
\hline
\end{tabular}


Table 3. The effect of sodium butyrate supplementation on health status of calves

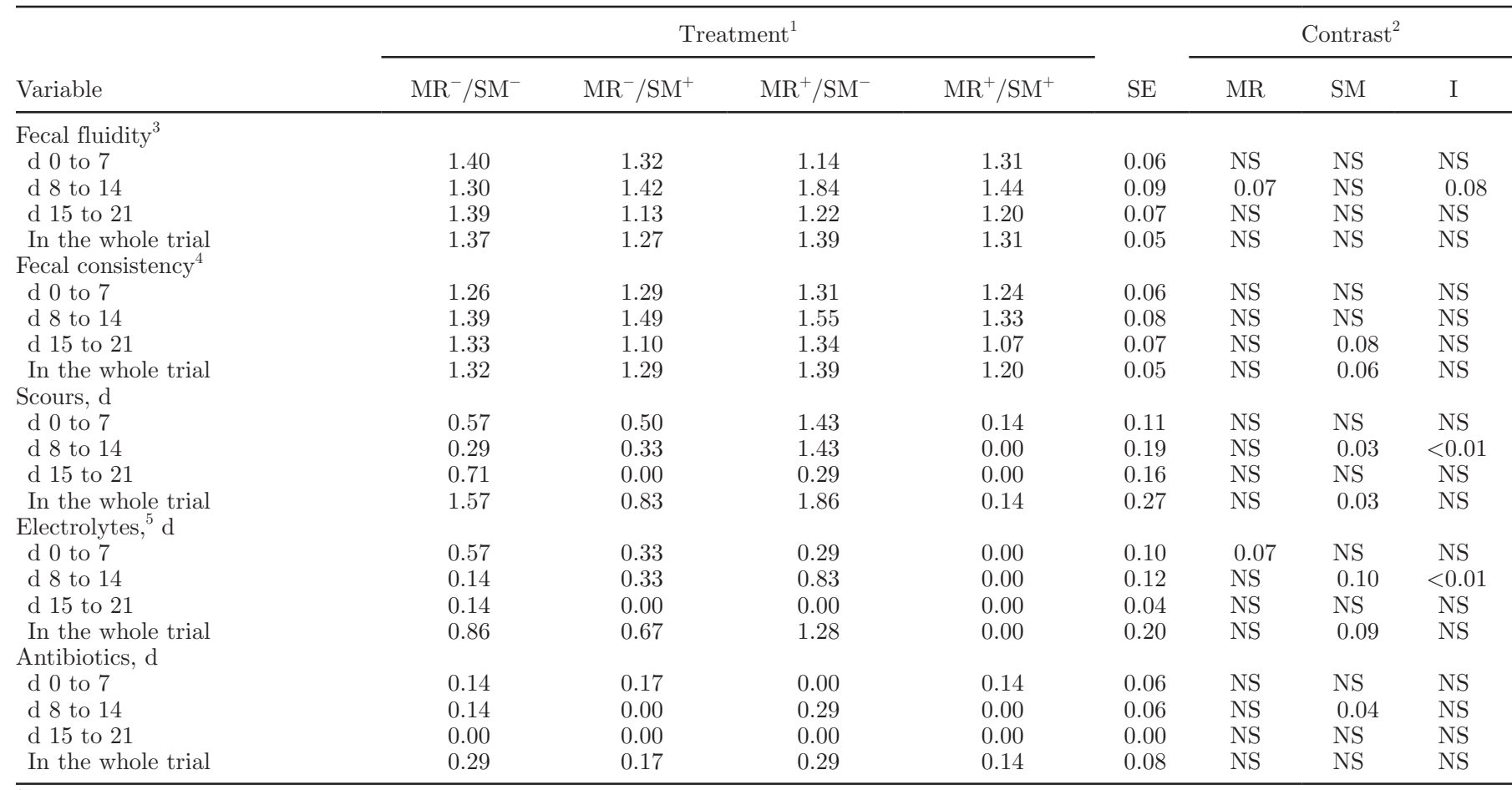

${ }^{1} \mathrm{MR}=$ milk replacer containing $0(-)$ or $0.3 \%(+)$ of sodium butyrate; $\mathrm{SM}=$ calf starter mixture containing $0(-)$ or $0.6 \%(+)$ of encapsulated within triglyceride matrix sodium butyrate.

${ }^{2} \mathrm{MR}=$ main effects of $\mathrm{MR}^{+}$vs. $\mathrm{MR}^{-} ; \mathrm{SM}=$ main effects of $\mathrm{SM}^{+}$vs. $\mathrm{SM}^{-} ; \mathrm{I}=$ interaction of main effects.

${ }^{3}$ Significant time effect $(P<0.01)$ and time $\times$ treatment interaction $(P=0.03)$.

${ }^{4}$ Significant time effect $(P=0.04)$.

${ }^{5}$ Significant time $\times$ treatment interaction $(P=0.02)$.

tion of the rumen, those from the $\mathrm{MR}^{+} / \mathrm{SM}^{+}$and $\mathrm{MR}^{-} /$ $\mathrm{SM}^{+}$groups intermediate, and those from the $\mathrm{MR}^{-} /$ $\mathrm{SM}^{-}$group had the shortest. A similar tendency toward differences in papillae width between treatments in this rumen location was shown (interaction $\mathrm{MR} \times \mathrm{SM} ; P$ $=0.09$ ). Butyrate supplementation into SM tended to decrease $(P<0.08)$ tunica muscularis thickness in the cranial ventral sac of the rumen.

\section{DISCUSSION}

Results of the study confirmed previously shown positive effects of dietary SB on the growth and health of calves (Hill et al., 2007a,b; Guilloteau et al., 2009). However, the most effective method of SB supplementation (MR or SM) has not been defined adequately. To the best of our knowledge, it is shown for the first time that the method of SB supplementation may differentially affect performance, some metabolic intermediates, and forestomach development in newborn calves.

\section{Performance and Health}

A positive effect of $\mathrm{MR}^{+}$on performance of newborn calves is attributed mainly to its stimulatory effect on the small intestine and pancreas development and function (Guilloteau et al., 2004, 2009, 2010). Because the MR offered in the present study contained soy protein, which is known to have a negative effect on calf small intestine development (Seegraber and Morrill, 1986; Drackley et al., 2006), the positive effect of $\mathrm{MR}^{+}$on growth parameters of calves is not surprising. On the other hand, low StDt intake from d 0 to 14 of the trial explains the lack of effect of $\mathrm{SM}^{+}$on $\mathrm{ADG}$ and $\mathrm{BW}$ of calves. Negligible StDt intake at the beginning of the trial and a positive effect of $\mathrm{SM}^{+}$on StDt intake, which only occurred during the last week of the study, may explain the lack of additive effect of simultaneous supplementation of SB in MR and SM on growth parameters of calves during the whole trial period.

Even in groups of calves fed $\mathrm{MR}^{+}$, which exhibited the greatest $\mathrm{BW}$ gain, $\mathrm{ADG}$ was below those calculated from nutrient intake (NRC, 2001). It could be partially a result of gradual incorporation of restricted amounts of MR during the first week of the trial or the presence of soy protein in the MR (Seegraber and Morrill, 1986; Drackley et al., 2006). However, from d 8 to 21 of the study, when nutrient intake fully covered the requirements, ADG was still below expected. Thus, although 
Table 4. The effect of sodium butyrate supplementation on concentration of blood parameters in calves

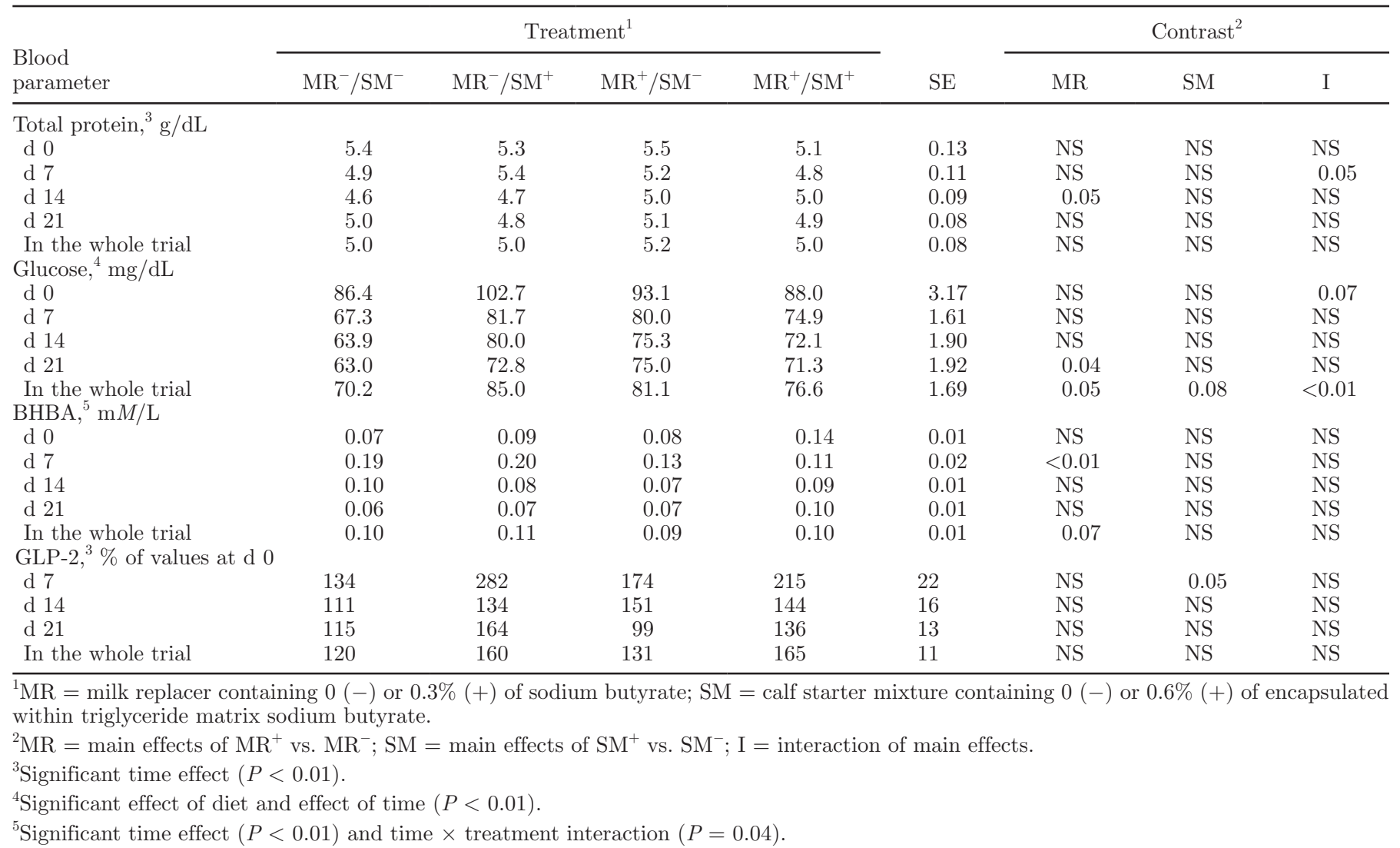

it seems that $\mathrm{MR}^{+}$positively affected performance of calves, it was still unable to fully compensate for the imperfections in MR. Nevertheless, taking into account poorer performance and also slower rumen development in calves fed $\mathrm{MR}^{-}$, each method of $\mathrm{SB}$ supplementation, at least partially, reverses these negative effects and should be acknowledged.

When using early weaning management schemes, adequate solid feed intake is an even more important parameter than daily gain because it determines growth and health after weaning (Greenwood et al., 1997a). Despite the positive effect of $\mathrm{MR}^{+}$on $\mathrm{BW}$, starter diet intake was unaffected. Similarly Hill et al. (2007a) did not observe an effect of SB inclusion in MR on solid feed intake, although BW of calves was positively affected. In newborn calves, solid feed intake depends on the development of rumen capacity and mass (Khan et al., 2007; Kristensen et al., 2007) as well as rumen microflora and papillae, which affect the efficiency of nutrient digestion and absorption. Because it was assumed that $\mathrm{SM}^{+}$could directly stimulate rumen epithelium development and, as a result, the area of absorption of digestion products, it may explain the higher StDt intake in calves from the $\mathrm{MR}^{-} / \mathrm{SM}^{+}$and $\mathrm{MR}^{+} / \mathrm{SM}^{+}$ groups. Higher StDt intake in calves from the $\mathrm{MR}^{-} /$
$\mathrm{SM}^{+}$and $\mathrm{MR}^{+} / \mathrm{SM}^{+}$groups also explains the higher reticulorumen weight, which increases in newborn calves as solid feed intake increases (Kristensen et al., 2007). However, addition of SB in MR also positively affected papillae development and reticulorumen weight. The latter increases as rumen capacity increases (Kristensen et al., 2007). Taken together, results of the current study may suggest a different mechanism of SB action on feed intake when supplemented in MR or SM and that may explain the lack of an additive effect of SB supplementation both in MR and SM on StDt intake.

A positive effect of SB supplementation in MR on the health status of calves was shown previously (Hill et al., 2007a). In the current study, $\mathrm{MR}^{+}$tended to positively affect calves health in the first $2 \mathrm{wk}$ of the trial (thicker feces and fewer electrolyte therapies). Well-known antiinflammatory, cytoprotective, and antibacterial properties of butyric acid (Gibson et al., 1998; Rabbani et al., 1999) could be beneficial in the period of life covering MR implementation to the diet. On the other hand, addition of SB in SM had a more pronounced effect on the health of calves in the later period of the trial $(\mathrm{d}$ 8 to 21 ), when solid feed intake increased. Taking into account that $\mathrm{MR}^{+}$positively affected calf health in first 2 wk of the trial and $\mathrm{SM}^{+}$in its later period, it may 
Table 5. The effect of sodium butyrate supplementation on stomach development in calves

\begin{tabular}{|c|c|c|c|c|c|c|c|c|}
\hline Item & \multicolumn{4}{|c|}{ Treatment $^{1}$} & $\mathrm{SE}$ & \multicolumn{3}{|c|}{ Contrast $^{2}$} \\
\hline \multicolumn{9}{|l|}{ Weight, $\%$ of BW } \\
\hline Reticulorumen & 0.64 & 0.82 & 0.70 & 0.74 & 0.04 & NS & NS & 0.05 \\
\hline Omasum & 0.18 & 0.19 & 0.17 & 0.16 & 0.01 & NS & NS & NS \\
\hline Abomasum & 0.65 & 0.63 & 0.60 & 0.58 & 0.02 & NS & NS & NS \\
\hline Omasum & 12 & 12 & 11 & 11 & 0.2 & NS & NS & NS \\
\hline Abomasum & 45 & 39 & 42 & 39 & 1.0 & NS & 0.09 & NS \\
\hline \multicolumn{9}{|l|}{ Cranial dorsal sac } \\
\hline Papillae length, $\mu \mathrm{m}$ & 314 & 457 & 443 & 516 & 22 & 0.08 & 0.02 & NS \\
\hline Papillae width, $\mu \mathrm{m}$ & 150 & 185 & 186 & 228 & 8 & 0.02 & $<0.01$ & NS \\
\hline Tunica muscularis, $\mu \mathrm{m}$ & 1,345 & 1,209 & 1,437 & 1,320 & 50 & NS & NS & NS \\
\hline \multicolumn{9}{|l|}{ Cranial ventral sac } \\
\hline
\end{tabular}

${ }^{1} \mathrm{MR}=$ milk replacer containing $0(-)$ or $0.3 \%(+)$ of sodium butyrate; SM = calf starter mixture containing $0(-)$ or $0.6 \%(+)$ of encapsulated within triglyceride matrix sodium butyrate.

${ }^{2} \mathrm{MR}=$ main effects of $\mathrm{MR}^{+}$vs. $\mathrm{MR}^{-} ; \mathrm{SM}=$ main effects of $\mathrm{SM}^{+}$vs. $\mathrm{SM}^{-} ; \mathrm{I}=$ interaction of main effects.

explain the most pronounced effect of SB on health status in calves from the $\mathrm{MR}^{+} / \mathrm{SM}^{+}$group.

\section{Blood Parameters}

As glucose is the preferred energy substrate for preruminant calves (Donkin and Armentano, 1995), its higher plasma concentration in calves fed $\mathrm{MR}^{+}$or $\mathrm{SM}^{+}$should be considered as a positive outcome of this supplementation, at least in this period of life. Higher serum total protein in calves fed $\mathrm{MR}^{+}$also should be considered as a positive effect of SB supplementation, indicating greater accessibility of proteins for the developing organism. Moreover, lower plasma BHBA concentrations in calves fed $\mathrm{MR}^{+}$further justify $\mathrm{SB}$ addition to MR. Although plasma BHBA concentration is a widely accepted marker of rumen function development in newborn calves (Quigley et al., 1991; Kristensen et al., 2007), its higher concentration at d 7 of the trial in calves fed $\mathrm{MR}^{-}$should be rather linked to the hypoglycemia and negative energy balance indicated by BW lost, not faster rumen function development, because solid feed intake was negligible in this period of the trial.

Our previous study showed that simultaneous supplementation of SB in MR and SM accelerated rumen development and increased plasma GLP-2 in calves (Górka et al., 2009). In this study, we were able to show that GLP-2 secretion was stimulated mainly when SB was supplemented in SM. However, it was recently shown that mRNA expression of the GLP-2 receptor in the rumen is negligible (Taylor-Edwards et al., 2010) and, therefore, GLP-2 seems to play a minor role in regulation of forestomach development. On the other hand, GLP-2 is known to be an important stimulator of intestine development (Burrin et al., 2003) and calves fed $\mathrm{SM}^{+}$had higher small intestine weight as compared with those fed $\mathrm{SM}^{-}$(our unpublished results). Górka et al. (2011) showed positive correlation between small intestine weight and reticulorumen weight in newborn calves. Thus, $\mathrm{SM}^{+}$may stimulate development of rumen weight not only directly, but also indirectly via stimulatory effects on plasma GLP-2 concentration and small intestine development.

\section{Rumen Development}

Sodium butyrate supplementation both in MR and SM positively affected reticulorumen weight (expressed as a percentage of whole stomach weight) and papillae length and width, partially supporting our initial hypothesis. On the other hand, no additive effect of concomitant supplementation of SB in both MR and $\mathrm{SM}$ on rumen development was discerned in this study.

An especially pronounced effect of SB on rumen development could be expected when it was a component of SM. The aim of this method of SB delivery was to stimulate directly rumen epithelial cell proliferation, as was shown when ruminal infusions of sodium salt of butyric acid were used (Tamate et al., 1962; Mentschel et al., 2001). This way of SB supplementation also resulted in higher StDt intake, which could additionally stimulate reticulorumen development (Tamate et al., 1962; Kristensen et al., 2007) also as a result of higher 
energy and protein intake. In fact, the calves from the $\mathrm{MR}^{-} / \mathrm{SM}^{+}$group had the highest reticulorumen weight and better developed papillae as compared with calves from the $\mathrm{MR}^{-} / \mathrm{SM}^{-}$group. However, addition of $\mathrm{SB}$ to MR also positively affected rumen development without enhancing StDt intake. Moreover, papillae in the ruminal ventral sac from calves fed $\mathrm{MR}^{+}$, with or without SB in SM, were longer than in calves from the $\mathrm{MR}^{-} / \mathrm{SM}^{+}$group.

It seems that a positive effect of SB supplementation in MR on rumen development was a result of SB effect on animal growth, health, and probably metabolic status, as indicated by the positive effect on investigated metabolic indicators. Reticulorumen weight increases as BW increases even when solid feed is not offered (Tamate et al., 1962) and calves fed $\mathrm{MR}^{+}$tended to have higher BW as compared with those fed $\mathrm{MR}^{-}$. It is also known that glucose is a preferred energy substrate for rumen epithelial cells in the first weeks of life of ruminants (Giesecke et al., 1985; Baldwin and Jesse, 1992) and circulating glucose concentration was increased as a result of SB supplementation in MR. Higher serum protein concentration in calves fed $\mathrm{MR}^{+}$ may also suggest greater AA accessibility for developing forestomach tissues.

Taking into account that both $\mathrm{MR}^{+}$and $\mathrm{SM}^{+}$positively affected rumen development, this lack of an additive effect of simultaneous SB supplementation in MR and SM is not fully consistent with our hypothesis. In the present study, some interactions between main effects for some parameters of rumen development were shown, which indicates a complexity of mechanisms regulating development. Coarse starter and whole corn grain intake, which was the highest in calves fed $\mathrm{SM}^{+}$, could lead to rumen epithelium desquamation and numerically shorter papillae in these animals (Greenwood et al., 1997b). On the other hand, numerically longer and wider papillae, but lower reticulorumen weight, in calves from the $\mathrm{MR}^{+} / \mathrm{SM}^{-}$and $\mathrm{MR}^{+} / \mathrm{SM}^{+}$groups compared with those from the $\mathrm{MR}^{-} / \mathrm{SM}^{+}$group could be attributed to the differences in StDt intake between treatments and the discussed effects of method of SB delivery on distal GIT and pancreatic functions. Ultimately, these effects are likely to affect nutrient accessibility for developing calf tissues.

Taken together, mechanisms that control rumen development in newborn calves need further explanation. Specific definition of mechanisms of SB action is also needed. Exploration into these mechanisms will enhance nutritional programs for calf rearing, especially for early weaning protocols. Moreover, long-term effects of SB supplementation in MR and SM on GIT development and performance should be also determined.

\section{CONCLUSIONS}

Based on these results, it can be concluded that addition of SB in MR positively affected BW gain, health, and some metabolic intermediates and it stimulated rumen development indirectly, whereas SB supplementation in SM stimulated rumen development directly. The $\mathrm{MR}^{+}$and $\mathrm{SM}^{+}$were not additive in their effect on rumen development. However, addition of SB both in MR and SM can still be recommended for rearing calves. Such a method of SB supplementation exhibited a positive effect on rumen development but also had the most pronounced effect on the performance of calves. It increased growth rate and StDt intake and demonstrably affected the health status of animals. Nevertheless, to fully justify SB supplementation both in MR and SM, long-term effects should be determined. A better explanation of mechanisms involved is also needed.

\section{ACKNOWLEDGMENTS}

This study was funded by the Ministry of Science and Higher Education of Poland (Grant no. 1164/ P01/2006/31) and partially by European Social Funds and National Budget of Poland. The authors acknowledge to the Top Farms (Głubczyce, Poland) staff for help in collecting data.

\section{REFERENCES}

AOAC. 2000. Official Methods of Analysis. 17th ed. Association of Official Analytical Chemists, Washington, DC.

Baldwin, R. L. VI, and B. W. Jesse. 1992. Developmental changes in glucose and butyrate metabolism by isolated sheep ruminal cells. J. Nutr. 122:1149-1153.

Baldwin, R. L. VI, K. R. McLeod, J. L. Klotz, and R. N. Heitmann. 2004. Rumen development, intestinal growth and hepatic metabolism in the pre- and postweaning ruminant. J. Dairy Sci. 87(E. Suppl.):E55-E65.

Blättler, U., H. M. Hammon, C. Morel, C. Philipona, A. Rauprich, V. Romé, I. Le Huërou-Luron, P. Guilloteau, and J. W. Blum. 2001. Feeding colostrum, its composition and feeding duration variably modify proliferation and morphology of the intestine and digestive enzyme activities of neonatal calves. J. Nutr. 131:1256-1263.

Burrin, D., X. Guan, B. Stoll, Y. M. Petersen, and P. T. Sangild. 2003. Glucagon-like peptide 2: A key link between nutrition and intestinal adaptation in neonates? J. Nutr. 133:3712-3716.

Conway, E. J. 1962. Ammonia. General method. Pages 98-100 in Microdiffusion Analysis and Volumetric Error. Crosby Lockwood and Son Ltd., London, UK.

Donkin, S. S., and L. E. Armentano. 1995. Insulin and glucagon regulation of gluconeogenesis in preruminating and ruminating bovine. J. Anim. Sci. 73:546-551.

Drackley, J. K., R. M. Blome, K. S. Bartlett, and K. L. Bailey. 2006. Supplementation of $1 \%$ L-glutamine to milk replacer does not overcome the growth depression in calves caused by soy protein concentrate. J. Dairy Sci. 89:1688-1693.

Erwin, E. S., G. J. Marco, and E. M. Emery. 1961. Volatile fatty acid analyses of blood and rumen fluid by gas chromatography. J. Dairy Sci. 44:1768-1771.

Faisant, N., V. Planchot, F. Kozlowski, M. Pacouret, P. Colonna, and M. Champ. 1995. Resistant starch determination adapted to 
products containing high level of resistant starch. Sci. Aliments 15:83-89.

Gibson, P. R., D. Kilias, O. Rosella, J. M. Day, M. Abbott, C. F. Finch, and G. P. Young. 1998. Effect of topical butyrate on rectal epithelial kinetics and mucosal enzyme activities. Clin. Sci. (Lond.) 94:671-676.

Giesecke, D., U. Beck, and B. Emmanuel. 1985. Ketogenic regulation by certain metabolites in rumen epithelium. Comp. Biochem. Physiol. B 81:863-867.

Górka, P., Z. M. Kowalski, P. Pietrzak, A. Kotunia, W. Jagusiak, and R. Zabielski. 2011. Is rumen development in newborn calves affected by different liquid feeds and small intestine development? J. Dairy Sci. 94:3002-3013.

Górka, P., Z. M. Kowalski, P. Pietrzak, A. Kotunia, R. Kiljańczyk, J. Flaga, J. J. Holst, P. Guilloteau, and R. Zabielski. 2009. Effect of sodium butyrate supplementation in milk replacer and starter diet on rumen development in calves. J. Physiol. Pharmacol. 60(Suppl. 3):47-53.

Greenwood, R. H., J. L. Morrill, and E. C. Titgemeyer. 1997a. Using dry feed intake as a percentage of initial body weight as a weaning criterion. J. Dairy Sci. 80:2542-2546.

Greenwood, R. H., J. L. Morrill, E. C. Titgemeyer, and G. A. Kennedy. 1997b. A new method of measuring diet abrasion and its effect on the development of the forestomach. J. Dairy Sci. 80:2534-2541.

Guilloteau, P., V. Romé, L. Le Normand, G. Savary, and R. Zabielski. 2004. Is Na-butyrate a growth factor in the preruminant calf? Preliminary results. J. Anim. Feed Sci. 13(Suppl. 1):393-396.

Guilloteau, P., G. Savary, Y. Jaguelin-Peyrault, V. Romé, L. Le Normand, and R. Zabielski. 2010. Dietary sodium-butyrate supplementation increases digestibility and pancreatic secretion in young milk fed calves. J. Dairy Sci. 93:5842-5850.

Guilloteau, P., R. Zabielski, J. C. David, J. W. Blum, J. A. Morisset, M. Biernat, J. Woliński, D. Laubitz, and Y. Hamon. 2009. Sodiumbutyrate as a growth promoter in milk replacer formula for young calves. J. Dairy Sci. 92:1038-1049.

Hartmann, B., A. H. Johnsen, C. Ørskov, K. Adelhorst, L. Thim, and J. J. Holst. 2000. Structure, measurement and secretion of human glucagon-like peptide-2. Peptides 21:73-80.

Hill, T. M., J. M. Aldrich, R. L. Schlotterbeck, and H. G. Bateman II. 2007a. Effects of changing the fat and fatty acid composition of milk replacers fed to neonatal calves. Prof. Anim. Sci. 23:135-143.

Hill, T. M., J. M. Aldrich, R. L. Schlotterbeck, and H. G. Bateman II 2007b. Effects of changing the fatty acid composition of calf starters. Prof. Anim. Sci. 23:665-671.

Hill, T. M., H. G. Bateman II, J. M. Aldrich, and R. L. Schlotterbeck. 2008. Effect of feeding different carbohydrate sources and amounts to young calves. J. Dairy Sci. 91:3128-3137.

Khan, M. A., H. J. Lee, W. S. Lee, H. S. Kim, K. S. Ki, T. Y. Hur, G. H. Suh, S. J. Kang, and Y. J. Choi. 2007. Structural growth, rumen development, and metabolic and immune responses of Holstein male calves fed milk through step-down and conventional methods. J. Dairy Sci. 90:3376-3387.
Kotunia, A., J. Woliński, D. Laubitz, M. Jurkowska, V. Romé, P. Guilloteau, and R. Zabielski. 2004. Effect of sodium butyrate on the small intestine development in neonatal piglets feed by artificial sow. J. Physiol. Pharmacol. 55(Suppl. 2):59-68.

Kristensen, N. B., J. Sehested, S. K. Jensen, and M. Vestergaard. 2007. Effect of milk allowance on concentrate intake, ruminal environment, and ruminal development in milk-fed Holstein calves. J. Dairy Sci. 90:4346-4355.

Larson, L. L., F. G. Owen, J. L. Albright, R. D. Appleman, R. C Lamb, and L. D. Muller. 1977. Guidelines toward more uniformity in measuring and reporting calf experimental data. J. Dairy Sci. 60:989-991.

Lesmeister, K. E., and A. J. Heinrichs. 2004. Effects of corn processing on growth characteristics, rumen development, and rumen parameters in neonatal dairy calves. J. Dairy Sci. 87:3439-3450.

Littell, R. C., P. R. Henry, and C. B. Ammerman. 1998. Statistical analysis of repeated measures data using SAS procedures. J Anim. Sci. 76:1216-1231.

Mazzoni, M., M. Le Gall, S. De Filippi, L. Minieri, P. Trevisi, J. Woliński, G. Lalatta-Costerbosa, J. P. Lallès, P. Guilloteau, and P. Bosi. 2008. Supplemental sodium butyrate stimulates different gastric cells in weaned pigs. J. Nutr. 138:1426-1431.

Mentschel, J., R. Leiser, C. Mülling, C. Pfarrer, and R. Claus. 2001. Butyric acid stimulates rumen mucosa development in the calf mainly by a reduction of apoptosis. Arch. Tierernahr. 55:85-102

Niwińska, B., and J. Strzetelski. 2005. Effects of type of liquid feed and feeding frequency on rumen development and rearing performance of calves. Ann. Anim. Sci. 5:125-134.

NRC. 2001. Nutrient Requirements of Dairy Cattle. National Academy Press, Washington, DC.

Quigley, J. D. III, L. A. Caldwell, G. D. Sinks, and R. N. Heitmann. 1991. Changes in blood glucose, nonesterified fatty acids, and ketones in response to weaning and feed intake in young calves. J. Dairy Sci. 74:250-257.

Rabbani, G. H., M. J. Albert, A. S. Hamidur Rahman, M. Moyenul Isalm, K. M. Nasirul Islam, and K. Alam. 1999. Short-chain fatty acids improve clinical, pathologic, and microbiologic features of experimental shigellosis. J. Infect. Dis. 179:390-397.

SAS Institute. 2002. The SAS System. Version 9.1. SAS Institute Inc., Cary, NC.

Seegraber, F. J., and J. L. Morrill. 1986. Effect of protein source in calf milk replacers on morphology and absorptive ability of small intestine. J. Dairy Sci. 69:460-469.

Tamate, H., A. D. McGilliard, N. L. Jacobson, and R. Getty. 1962. Effect of various dietaries on the anatomical development of the stomach in the calf. J. Dairy Sci. 45:408-420.

Taylor-Edwards, C. C., D. G. Burrin, J. C. Matthews, K. R. McLeod, J. J. Holst, and D. L. Harmon. 2010. Expression of mRNA for proglucagon and glucagon-like peptide-2 (GLP-2) receptor in the ruminant gastrointestinal tract and the influence on energy intake. Domest. Anim. Endocrinol. 39:181-193. 